\title{
University students' preference regarding social media content, internet usage and online friendship patterns
}

University students' preference

\author{
Asma Butt \\ Department of Sociology, Virtual University of Pakistan-M A Jinnah Campus, \\ Lahore, Pakistan and \\ Department of Sociology, University of the Punjab Quaid-i-Azam Campus, \\ Lahore, Pakistan
}

\begin{abstract}
Purpose - This study aimed to find out the web content accessed by university students and to compare the level of interaction with real-life friends and online friends.

Design/methodology/approach - In this study, the quantitative research design used, and the researcher collected data through the survey method. The population comprises all undergraduate students at the University of the Punjab, Lahore. The sample of 320 students, age ranges from 18 to 22 years from eight selected departments, collected through a simple random sampling technique and after extraction 284 questionnaires evaluated by using Statistical Package for Social Sciences (SPSS).

Findings - The findings of the study showed that students preferred activities on the Internet is to access social networking sites. Additionally, the mobile phone is the most commonly used device among university students to access the Internet. Furthermore, students mostly used Facebook to keep in touch with their old friends and talk on different topics more easily with their online friends as compared to real-life friends. The study also shows that the results of both the hypothesis are significant; therefore, no difference exists regarding time spent on the Internet in real-life friendship patterns and online friendship patterns.

Originality/value - The research was used to find out the difference between the online friendship and reallife friendship patterns of the two groups who use the Internet for less time and who spend more time on the Internet among the university students.
\end{abstract}

Keywords Internet, Social networking sites, Communication patterns, University students

Paper type Research paper

\section{Introduction}

The present study was an attempt to evaluate the use of the Internet and changing communication patterns because of social media among university students. As in today's world of information technology, university students spend most of their time on the Internet, it has become simpler to gather information about any individual or topic. Social media has changed the foundation of how university students communicate. Social media has created a new social order in Pakistani society; it has strengthened the online friendship but weakened the inter-personal relations. The Internet and social media have also redefined the value systems and cultural orientation more dangerously in Pakistani society. For the advancement of the Internet, social changes especially the value changes are non-

(C) Asma Butt. Published in Asian Association of Open Universities Journal. Published by Emerald Publishing Limited. This article is published under the Creative Commons Attribution (CC BY 4.0) license. Anyone may reproduce, distribute, translate and create derivative works of this article (for both commercial and non-commercial purposes), subject to full attribution to the original publication and authors. The full terms of this license may be seen at http://creativecommons.org/licences/by/4.0/ legalcode

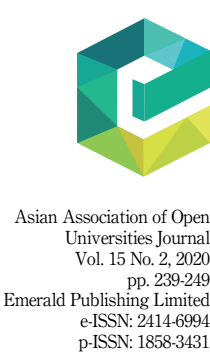

DOI 10.1108/A -IOUJ $1858-343$
Received 19 January 2020

Revised 21 June 2020 8 August 2020

Accepted 11 August 2020 
AAOUJ

15,2

240 ignorable. Therefore, with the growing number of Internet users in Pakistan and its everincreasing popularity among the youth, in particular, it is prime time that the researcher shed light on this matter and provided the upcoming researchers with better ideas.

The role and effect of technology in both personal and professional lives developed regularly. Seeing how individuals shape technology and how technology shapes individuals are important for those people and organizations who need to use the technologies in their working and individual lives (Professor Andy Lane, 2006). We apply technology in nearly all that we do in our everyday lives; we use technology for communication, learning and so much more (Ramey, 2013).

According to Ayub et al. (2014) advances in Information and Communication Technologies (ICTs) have enabled the Internet to serve as a platform not merely to seek information, yet additionally, to exchange thoughts and information with different users, and gain expert opinions using email, video chatting and other avenues. Technology has made it possible for us to access an enormous amount of information on the Internet.

According to Ruzgar (2005), the Internet is a global system of connections between computers that allows almost instant access to and dissemination of information. According to Teong and Ang (2016) the Internet has become the most fundamental part of daily life for most young adults and they mainly use it for education, information searching, entertainment, mail and social interaction purposes. Barnett and Benefield (2017) noted that the Internet has become accessible globally and has driven the world-wide integration of social, political and financial aspects.

As Internet is the most powerful source to connect people and social media is gaining its momentum at an unimaginable speed which shows that we, as social beings, need consistent association with one another and with the outside world. With the progress of the Internet, social networking sites (SNS) that is Facebook, Twitter, WhatsApp and Skype are increasingly becoming popular and have become the most up-to-date tools for connecting people across the world. Social media tools such as Facebook, Wikipedia, YouTube, WhatsApp, LinkedIn, blogging and Twitter have become universal because students use them constantly (Liu, 2010).

Bauer and Schedl (2019) argue that each day a large number of individuals overall send, get post, view and like a lot of messages through online SNSs. Students mostly use social media to discuss their feelings. All around the world, a huge number of individuals particularly youth have signed up to at least one SNS to develop their social relationships and to maintain the existing relations (Ukomadu, 2018).

According to a Global Digital Report, Pakistan's number of active social media users grew by $5.7 \%$ up to January 2019 (Farooq, 2019). The growth and use of SNSs in Pakistan have changed the communication and interaction patterns, particularly among youth. In the social world, youth is living a robotic life as opposed to idealistic life (Bala, 2014). Social media supremacy in Pakistani youth may lead to the weakening of interpersonal communication. Standlee (2018) observed that youth gather information through social media sites and use this information to reshape the perceptions about offline friends.

According to the Saudi Grand Mufti: "Social media site; Twitter is the source of all evil" (cleric, 2014). Internet was a source of credible information, but now because of social media, it has become a source of lies and falsehood.

A research study conducted across 15 countries identified students in higher education as being responsible for increasing the use of mobile computing devices, such as tablets and smartphones, with $67 \%$ attributing the technologies as being a factor in their academic success (Walker et al., 2013). As showed by AC Nielson's The Social Media Report 2012 surveys, "More individuals are using advanced mobile phones and tablets to get to the social media world and with greater availability, individuals have more opportunities to use social media” (AC Nielson, 2012). 
According to Giddens (1999), there is a global revolution going on in how we think of ourselves and how we form ties and connections with others. Helliwell and Huang (2013) had contrasted real life and online friendship networks as sources of satisfaction. Carter (2005) has outlined some issues involved in the development of human relationships in cyberspace. The study investigated how geographically distant individuals are coming together on the Internet to occupy new sorts of social spaces or virtual groups. Individuals "live in" and "build" these additional spaces to propose that the Internet is anything but placeless cyberspace distinct from the real world. She outlines the broader context of the Internet and society that how individuals build and maintain relationships in cyberspace.

Lu et al. (2017) argue that with the popularity of social media, online social networks have rapidly developed and revolutionized the way people connect. People are using the Internet not only to maintain the existing offline friends but to create new online friends. These friendships originated online may even lead to face-to-face communications later in the physical world that is offline friendship.

Social media has prevailed so much in the lives of university students that their communication patterns have changed. It has become an important tool for self-expression and self-presentation. With the advancement in technological devices, mobile phones have made expedient communication desirable and real-life friendships are becoming redundant. Moreover, the presence of smartphones is catalyzing the phenomenon of addiction for Internet and social networking among university students.

\section{Objectives}

(1) To find out the web content accessed by university students.

(2) The extent to which university students use the Internet.

(3) To compare the level of interaction with real friends and online friends.

\section{Research hypothesis.}

H1. There is a significant mean difference in the online friendship patterns of the two groups who use the Internet for less time and who spend more time on the Internet.

H2. There is a significant mean difference in the real-life friendship patterns of the two groups who use the Internet for less time and who spend more time on the Internet.

\section{Methodology}

The present research was a quantitative study and survey research design was used to collect data from students of the University of the Punjab, Lahore. A self-designed questionnaire comprising three sections has used. The structure of the questionnaire was close-ended. The population comprises all undergraduate students of the University of the Punjab, Lahore. A sample of 320 undergraduate students, age ranges from 18 to 22 years, of the second and fourth semester of BS Honors selected from eight departments of the University of the Punjab, Lahore. The researcher adopted the simple random sampling technique, which is a probability sampling technique for the study because it results in representative samples and eliminates bias from the selection method.

\section{Data analysis and results}

To collect the requisite data, a self-designed questionnaire comprising three sections has used. A total of 320 respondents included in the study, but after extraction 284 questionnaires 
AAOUJ

15,2

\section{2}

Table 1.

Percentage distribution of respondents about hours spend on internet surfing evaluated and the researcher analyzed data using Statistical Package for Social Sciences (SPSS) software. To describe, categorize and summarize the data, descriptive statistics calculated and the total of each is not equal to 284 respondents because of missing data. To investigate the hypothesis, the researcher used inferential statistics. Further, independent sample $t$-test applied to see the difference between the online friendship patterns and real-life friendship patterns.

\section{Demographic information}

The survey collected student demographic information regarding their gender, age, department, residence and language to find out if these variables would affect student perceptions and attitudes toward Internet usage and friendship patterns. In terms of age, the mean age of the respondents was 19.3, and respondent's lies in the age group of 18-22 years. Furthermore, the majority of the students who are $89.1 \%$ were studying in the 2nd semester of their study and $10.9 \%$ were studying in the 4 th semester. Out of the total respondents, $41.9 \%$ were males and $58.1 \%$ were females. Furthermore, it identified that majority of the respondents who are $54.6 \%$ had their own houses while $45.4 \%$ lived in rented houses or hostels. Most of the participants who are $13.7 \%$ of students included in the study were from the Institute of Agricultural Sciences. 11.6\% students were from College of Earth and Environmental Sciences (CEES), 13.4\% were from Department of Space Science, 12\% were from Institute of Geology and Department of Social Work respectively, 12.7\% were from Institute of Communication Studies, 13\% were from Institute of Social and Cultural Studies (ISCS) and 11.6\% students were from Institute of Chemical Engineering and Emerging Technologies. Furthermore, the most common and widely spoken primary language of respondents is Urdu and the second common spoken language is Punjabi, while few respondents also spoke English and other languages.

\section{Internet surfing}

Section 2 includes questions related to the web content accessed by university students, the purpose of using the Internet and the purpose of Facebook usage. Percentage analysis was used to analyze and interpret the data.

According to the table, most of the students who are $35.9 \%$ used the Internet over $5 \mathrm{~h}$ per day. $33.5 \%$ spend $3-5 \mathrm{~h}$ per day, $29.6 \%$ spend $1-3 \mathrm{~h}$ per day while only $1.1 \%$ spend less than one hour per day and the table shows that all the students spend time on the Internet but the frequency of their Internet usage daily is different. The table represents that students mostly use the Internet over $5 \mathrm{~h}$ per day, which is an increasing trend in spending time on the Internet (see Table 1).

The above table shows the frequency distribution of device owners for using the Internet which shows that most of the students who are $89.1 \%$ have their device (phone and computer) for using the Internet while $10.9 \%$ have not (see Table 2 ).

The above table explains about multiple categories of accessing the Internet through the device and the frequency of accessing it. The first category of computer explains that 65

\begin{tabular}{lcr}
\hline Categories & Frequency & Percentage \\
\hline Less than one hour & 3 & 1.1 \\
$1-3 \mathrm{~h}$ & 84 & 29.6 \\
$3-5 \mathrm{~h}$ & 95 & 33.5 \\
More than $5 \mathrm{~h}$ & 102 & 35.9 \\
Total & 284 & 100
\end{tabular}


respondents who are $22.9 \%$ of the total population are the most responses who access the Internet through a computer, whereas 104 responses that are $36.6 \%$ of the total population explains that they access Internet sometimes through the computer, the remaining 99 responses that are $34.9 \%$ of the total population are not at all accessing Internet through the computer.

It explains the second category laptop that $28.2 \%$ of the most responses who access the Internet through the laptop, whereas $47.9 \%$ explains that they access the Internet sometimes through the laptop, the remaining $20.4 \%$ are not at all accessing Internet through the laptop.

It explains the third category mobile phone that $56.7 \%$ of the most responses who access the Internet through mobile phones, whereas 30.6\% explains that they access the Internet sometimes through mobile phone, the remaining which are only $9.5 \%$ of the total population is not at all accessing Internet through mobile phone.

It explains the final category tablet that $41.9 \%$ of the most responses who access the Internet through the tablet, whereas $21.1 \%$ explain that they access the Internet sometimes through the tablet, the remaining $34.2 \%$ are not at all accessing Internet through the tablet (see Table 3).

The table explains multiple categories of purpose levels of respondents for using the Internet. The first category of time pass entertainment explains that 134 respondents who are $47.2 \%$ of the total population are the most responses who use the Internet for time pass entertainment mostly, whereas 102 responses that are $35.9 \%$ of the total population explains that they use the Internet for time pass entertainment sometimes, the remaining 40 responses that are $14.1 \%$ of the total population are not at all use the Internet for time pass entertainment.

The second category relationship development explains that $26.4 \%$ of the most responses that use the Internet for relationship development mostly, whereas $37.3 \%$ explain that they use the Internet for relationship development sometimes, the remaining $33.5 \%$ are not at all using the Internet for relationship development.

The third category trend following explains that $31.3 \%$ of the most responses that use the Internet for trend following mostly, whereas 34.9\% explain that they use the Internet for trend following sometimes, the remaining $31 \%$ are not at all using the Internet for trend following.

The next category searching for information about the study explains that $50.4 \%$ of the most responses that search information by using the Internet for study purpose,

\begin{tabular}{lcc}
\hline Categories & Frequency & Percentage \\
\hline Yes & 253 & 89.1 \\
No & 31 & 10.9 \\
Total & 284 & 100
\end{tabular}

\section{University students' preference}

Table 2.

Percentage distribution of respondents about device own for using the Internet

\begin{tabular}{|c|c|c|c|c|c|}
\hline Categories & Most of the time & Sometimes & Not at all & Total & \\
\hline Computer & $\begin{array}{l}65 \\
22.9 \%\end{array}$ & $\begin{array}{l}104 \\
36.6 \%\end{array}$ & $\begin{array}{l}99 \\
34.9 \%\end{array}$ & $\begin{array}{l}268 \\
94.4 \%\end{array}$ & \\
\hline Laptop & $\begin{array}{l}80 \\
28.2 \%\end{array}$ & $\begin{array}{l}136 \\
47.9 \%\end{array}$ & $\begin{array}{l}58 \\
20.4 \%\end{array}$ & $\begin{array}{l}274 \\
96.5 \%\end{array}$ & $\begin{array}{r}\text { Table } 3 . \\
\text { Percentage }\end{array}$ \\
\hline Mobile phone & $\begin{array}{l}161 \\
56.7 \%\end{array}$ & $\begin{array}{l}87 \\
30.6 \%\end{array}$ & $\begin{array}{l}27 \\
9.5 \%\end{array}$ & $\begin{array}{l}275 \\
96.8 \%\end{array}$ & $\begin{array}{r}\text { distribution of } \\
\text { respondents about }\end{array}$ \\
\hline Tablet & $\begin{array}{l}119 \\
41.9 \%\end{array}$ & $\begin{array}{l}60 \\
21.1 \%\end{array}$ & $\begin{array}{l}97 \\
34.2 \%\end{array}$ & $\begin{array}{l}276 \\
97.25 \%\end{array}$ & $\begin{array}{l}\text { accessing the Internet } \\
\text { through device }\end{array}$ \\
\hline
\end{tabular}


AAOUJ 15,2

\section{4}

Table 4.

Percentage distribution of respondents about the purpose of using the Internet whereas $40.8 \%$ explain that they use the Internet sometimes for searching information for study purpose, the remaining which are only $6 \%$ are not at all using Internet for study purpose.

The next category watching the movie explains that $24.3 \%$ of the most responses that use the Internet for watching the movie, whereas 53.9\% explain that they use the Internet sometimes for watching the movie, the remaining $18.7 \%$ are not at all using Internet for watching the movie.

The final category chatting with friends explains that $41.9 \%$ of the most responses that use the Internet for chatting with friends, whereas $41.5 \%$ explain that they use the Internet sometimes for chatting with friends, the remaining $13 \%$ are not at all using the Internet for chatting with friends (see Table 4).

The table explains multiple categories of doing activities online. The first category of social networking (Facebook App and Twitter App, etc.) explains that 126 respondents that are $44.4 \%$ of the total population are the most responses who like doing social networking (Facebook and Twitter, etc.) mostly, whereas 83 responses that are $29.2 \%$ of the total population explain that they like doing social networking (Facebook and Twitter, etc.) sometimes, the remaining 61 responses that are $21.5 \%$ of the total population are not at all like to do social networking (Facebook and Twitter, etc.).

The second category explains web browsing that $41.5 \%$ of the most responses that like doing web browsing mostly, whereas $41.9 \%$ explain that they like doing web browsing sometimes, the remaining $14.1 \%$ are not at all like to web browsing.

The third category explains instant messenger (WhatsApp and Facebook, etc.) that $50 \%$ of the most responses that like doing instant messenger (WhatsApp and Facebook, etc.) mostly, whereas $35.9 \%$ explain that they like doing instant messenger (WhatsApp and Facebook, etc.) sometimes, the remaining $11.3 \%$ are not at all like to do instant messenger (WhatsApp and Facebook, etc.).

The next category of music that $50 \%$ of the most responses who like listening to music mostly, whereas $37.7 \%$ explains that they like listening to music sometimes, the remaining which are only $9.9 \%$ are not at all like to listen to music.

The next category of movies that $37 \%$ of the most responses who like watching movies mostly, whereas $42.6 \%$ explains that they like watching movies sometimes, the remaining $17.3 \%$ are not at all like to watch movies.

The next category of Youtube that $47.5 \%$ of the most responses who like doing Youtube mostly, whereas $38.7 \%$ explains that they like doing Youtube sometimes, the remaining $11.3 \%$ are not at all like doing Youtube.

\begin{tabular}{lcccc}
\hline Categories & Most of the time & Sometimes & Not at all & Total \\
\hline Time pass entertainment & 134 & 102 & 40 & 276 \\
Relationship development & $47.2 \%$ & $35.9 \%$ & $14.1 \%$ & $97.2 \%$ \\
& 75 & 106 & 95 & 276 \\
Trend following & $26.4 \%$ & $37.3 \%$ & $33.5 \%$ & $97.2 \%$ \\
& 89 & 99 & 88 & 276 \\
Searching for information about the study & $31.3 \%$ & $34.9 \%$ & $31 \%$ & $97.2 \%$ \\
& 143 & 116 & 17 & 276 \\
Watching movie & $50.4 \%$ & $40.8 \%$ & $6 \%$ & $97.2 \%$ \\
Chatting with friends & 69 & 153 & 53 & 275 \\
& $24.3 \%$ & $53.9 \%$ & $18.7 \%$ & $96.8 \%$ \\
& 119 & 118 & 37 & 274 \\
& $41.9 \%$ & $41.5 \%$ & $13 \%$ & $96.5 \%$
\end{tabular}


The final category academic purpose explains that $46.5 \%$ of the most responses who like doing academic purpose activities online mostly, whereas $40.5 \%$ explains that they like doing academic purpose activities online sometimes, the remaining $10.6 \%$ are not at all like doing academic purpose activities online (see Table 5).

The table explains multiple categories of purpose level of respondents for using Facebook. The first category of Facebook users to know about online friend's activity explains that 109 respondents who are $38.4 \%$ of the total population are the most responses who use Facebook to know about online friend's activity, whereas 77 responses that are $27.1 \%$ of the total population explains that they sometimes use Facebook to know about online friend's activity, the remaining 88 responses that are $31 \%$ of the total population are not at all using Facebook to know about online friend's activity.

It explains the second category of Facebook users to know about online friend's likes and dislikes that $38.7 \%$ of the most responses who use Facebook to know about online friend's likes and dislikes, whereas $26.1 \%$ explain that they sometimes use Facebook to know about online friend's likes and dislikes, the remaining $31.3 \%$ are not at all using Facebook to know about online friend's likes and dislikes.

It explains the third category of Facebook users to know about online friend's views that $39.8 \%$ of the most responses who use Facebook to know about online friend's views, whereas $28.2 \%$ explain that they sometimes use Facebook to know about online friend's views, the remaining $28.5 \%$ are not at all using Facebook to know about online friend's views.

It explains the next category of Facebook users to know about online friend's secrets that $28.9 \%$ of the most responses who use Facebook to know about online friend's secrets, whereas $28.5 \%$ explain that they sometimes use Facebook to know about online friend's secrets, the remaining $39.1 \%$ are not at all using Facebook to know about online friend's secrets.

It explains the next category of Facebook users to keep in touch with old friends that $47.9 \%$ of the most responses who use Facebook to keep in touch with old friends, whereas $25.4 \%$ explain that they sometimes use Facebook to keep in touch with old friends, the remaining $22.5 \%$ are not at all using Facebook to keep in touch with old friends.

It explains the next category of Facebook users to learn more about other people in classes that $42.3 \%$ of the most responses who use Facebook to learn more about other people in their classes, whereas $25.7 \%$ explain that they sometimes use Facebook to learn more about other people in their classes, the remaining $28.9 \%$ are not at all using Facebook to learn more about other people in their classes.

\begin{tabular}{|c|c|c|c|c|c|}
\hline Categories & Most of the time & Sometimes & Not at all & Total & \\
\hline \multirow{4}{*}{$\begin{array}{l}\text { Social networking (Facebook App and Twitter App, } \\
\text { etc.) } \\
\text { Web browsing }\end{array}$} & 126 & 83 & 61 & 270 & \\
\hline & $44.4 \%$ & $29.2 \%$ & $21.5 \%$ & $95.1 \%$ & \\
\hline & 118 & 119 & 40 & 277 & \\
\hline & $41.5 \%$ & $41.9 \%$ & $14.1 \%$ & $97.5 \%$ & \\
\hline \multirow[t]{2}{*}{ Instant messenger (WhatsApp and Facebook, etc.) } & 142 & 102 & 32 & 276 & \\
\hline & $50 \%$ & $35.9 \%$ & $11.3 \%$ & $97.2 \%$ & \\
\hline \multirow[t]{2}{*}{ Music } & 142 & 107 & 28 & 277 & \\
\hline & $50 \%$ & $37.7 \%$ & $9.9 \%$ & $97.5 \%$ & \\
\hline \multirow[t]{2}{*}{ Movies } & 105 & 121 & 49 & 275 & \\
\hline & $37 \%$ & $42.6 \%$ & $17.3 \%$ & $96.8 \%$ & Table 5. \\
\hline \multirow[t]{2}{*}{ Youtube } & 135 & 110 & 32 & 277 & Percentage \\
\hline & $47.5 \%$ & $38.7 \%$ & $11.3 \%$ & $97.5 \%$ & distribution of \\
\hline \multirow[t]{2}{*}{ Academic purpose } & 132 & 115 & 30 & 277 & respondents about \\
\hline & $46.5 \%$ & $40.5 \%$ & $10.6 \%$ & $97.5 \%$ & doing activities online \\
\hline
\end{tabular}

University students' preference 
AAOUJ 15,2

The final category of Facebook users to know about online friend's inner feelings explains that $34.5 \%$ of the most responses who use Facebook to know about online friend's inner feelings, whereas $22.9 \%$ explain that they sometimes use Facebook to know about online friend's inner feelings, the remaining $38.7 \%$ are not at all using Facebook to know about online friend's inner feelings (see Table 6).

\section{6}

\section{Real life vs online friendship}

Section 3 includes questions related to interaction patterns with online and real-life friends. Table 7 represents the mean score of each dimension of online friendship patterns and reallife friendship patterns based on a three-point Likert scale. Mean values of the elements of online friendship patterns range from $(M=1.87, \mathrm{SD}=0.830)$ I talk on different topics more

Table 6.

Percentage distribution of respondents about the purpose of using facebook

\begin{tabular}{lcccc}
\hline & Most of the & & & \\
Categories & time & Sometimes & Not at all & Total \\
\hline I use Facebook to know about my online friend's & 109 & 77 & 88 & 274 \\
activity & $38.4 \%$ & $27.1 \%$ & $31 \%$ & $96.5 \%$ \\
I use Facebook to know about my online friend's likes & 110 & 74 & 89 & 273 \\
and dislikes & $38.7 \%$ & $26.1 \%$ & $31.3 \%$ & $96.1 \%$ \\
I use Facebook to know about my online friend's views & 113 & 80 & 81 & 274 \\
& $39.8 \%$ & $28.2 \%$ & $28.5 \%$ & $96.5 \%$ \\
I use Facebook to know about my online friend's & 82 & 81 & 111 & 274 \\
secrets & $28.9 \%$ & $28.5 \%$ & $39.1 \%$ & $96.5 \%$ \\
I use Facebook to keep in touch with my old friends & 136 & 72 & 64 & 272 \\
& $47.9 \%$ & $25.4 \%$ & $22.5 \%$ & $95.8 \%$ \\
I use Facebook to learn more about other people in my & 120 & 73 & 82 & 275 \\
classes & $42.3 \%$ & $25.7 \%$ & $28.9 \%$ & $96.8 \%$ \\
I use Facebook to know about my online friend's inner & 98 & 65 & 110 & 273 \\
feelings & $34.5 \%$ & $22.9 \%$ & $38.7 \%$ & $96.1 \%$ \\
\hline
\end{tabular}

Indicator

Mean values

SD

Online friendship patterns

I talk on different topics more easily with my online friends

I talk more easily with my online friends about being in love

I have more conflicts with my online friends

I feel more connected with my online friends

I plan to go out more with my online friends

I depend on my online friends for help

I depend on my online friends for advice

I prefer my online friends over my real-life friends

Real-Life Friendship Patterns

I talk on different topics more easily with my real-life friends

I talk more easily with my real-life friends about being in love

I have more conflicts with my real-life friends

Table 7.

I feel more connected with my real-life friends

Descriptive statistics of online friendship patterns and real-life friendship patterns
I plan to go out more with my real-life friends

I depend on my real-life friends for help

I depend on my real-life friends for advice

I prefer my real-life friends over online friends

$\begin{array}{ll}1.87 & 0.830 \\ 1.58 & 0.730 \\ 2.03 & 0.790 \\ 1.99 & 0.830 \\ 2.05 & 0.828 \\ 2.08 & 0.826 \\ 2.06 & 0.821 \\ 2.12 & 0.841 \\ & \\ 1.69 & 2.001 \\ 1.90 & 0.825 \\ 1.95 & 0.803 \\ 1.73 & 0.798 \\ 1.66 & 0.788 \\ 1.73 & 0.832 \\ 1.74 & 0.807 \\ 1.86 & 0.844\end{array}$


easily with my online friends, $(M=1.58, \mathrm{SD}=0.730)$ I talk more easily with my online friends about being in love $(\mathrm{M}=2.03, \mathrm{SD}=0.790)$, I have more conflicts with my online friends. Overall results in this category show that majority of the students prefer their online friends $(M=2.12, \mathrm{SD}=0.841)$ over real-life friends $(M=1.58, \mathrm{SD}=0.730)$.

Results regarding real-life friendship patterns show that majority of the students have more conflicts with their real-life friends $(M=1.95, \mathrm{SD}=0.803)$. Students talk on different topics more easily with their online friends $(M=1.87, \mathrm{SD}=0.830)$ as compared to real-life friends $(M=1.69, \mathrm{SD}=2.001)$.

Hypothesis testing. The hypothesis tested by applying an independent sample $t$-test in which the students' spent time on the Internet taken as an independent variable and online friendship and real-life friendship taken as the dependent variable. Table 8 shows that a significant difference exists between less time to spend on the Internet and more time to spend on the Internet regarding online friendship patterns. Less time to spend on the Internet $(M=20.14, \mathrm{SD}=2.21)$ significantly differs from more time to spend on the Internet $(M=11.61, \mathrm{SD}=3.11)$.

The second hypothesis was regarding the real-life friendship patterns of the two groups who use the Internet for less time and who spend more time on the Internet. The result shows a significant difference between the two groups.

By comparing real-life friendship patterns with online friendship patterns as both the results of the hypothesis are significant, then no difference exists regarding time spent on the Internet in real-life friendship patterns and online friendship patterns.

\section{Discussion}

There are several studies in the literature investigating the use of the Internet and social media, but the focus of this study is to evaluate the use of the Internet, social media and compare interactions level among the students of the University of the Punjab, Lahore. The three sections presented in the data analysis are demographic information, Internet surfing and online vs real-life friendship patterns. Demographically, the number of female respondents was $58.1 \%$ of the total population, while male respondents were $41.9 \%$ of the total population. In terms of age, most of the respondents fall at 19 years. Moreover, the majority of the respondents speak Urdu as a primary language.

To understand the role of Internet and SNSs in university students' lives, we analyzed basic trends in Internet usage and activities performed on the Internet. Data from this study reveal several interesting findings on student's access to the Internet and their activities both on the Internet and on social media. The results showed that students use the mobile phone to access the Internet which shows that mobile phone is the most commonly used device to access Internet among university students and most of the respondents have their device to access the Internet.

The results also showed that the Internet has used extensively by undergraduate students and their preferred activities on the Internet were to access social networking (WhatsApp and Facebook), online chatting, music, movies, Youtube and searching for information about the

\begin{tabular}{llllll}
\hline Variable & Time dimension & $M$ & SD & $t$ & Sig \\
\hline Online friendship & Less time & 20.14 & 2.21 & 26.514 & 0.000 \\
& More time & 11.61 & 3.11 & & \\
Real-life friendship & Less time & 19.81 & 4.69 & 26.35 & 0.000 \\
& More time & 8.95 & 1.57 & &
\end{tabular}

University students' preference

$+$ 
AAOUJ 15,2

\section{8}

study. Furthermore, students mostly used Facebook to keep in touch with their old friends rather than to know about a friend's inner feelings or secrets, which shows that Facebook is an important venue for interaction and conversation among friends.

This study also compares the level of interaction with online and real-life friends. The results of the independent sample $t$-test showed that respondents are consistent with the study of Lu et al. (2017) conducted on interaction patterns on the Internet. The study shows that social media is changing the foundation of the ways of relationships among university students. The study also shows that the Internet and social media are the most common source of entertainment among university students in Pakistan.

\section{Conclusion}

Based on the findings of this study, the researcher can conclude that university students are engaged in using the Internet and social media sites which show that they are comfortable in using communication technology. Using the Internet, social media sites have shown rapid growth during recent years. Social media has prevailed so much in the lives of university students that their communication patterns have changed. It is strengthening the social relations and weakening the real-life relations. Additionally, the mobile phone is the most commonly used device among university students to access the Internet.

Internet use as one of the apparent effects of the modern world is an important tool for training the new generation. The Internet is everywhere, at home, at school and even in shopping centers in public places like airports, hospitals, etc. Undoubtedly, the Internet has mainly changed people's lives, a change compared with the change that telephone inventions brought about in the early twentieth century and television in the 1950s. The present study found that university students have accepted the Internet as a simple way of accessing the relevant information and one of the most common means for entertainment and research at the same time.

\section{References}

Ayub, A.F., Hamid, W.H. and Nawawi, M.H. (2014), "Use of the internet for academic purposes among students in Malaysian institutions of higher education", The Turkish Online Journal of Educational Technology, Vol. 13 No. 1, pp. 232-239.

Bala, D.K. (2014), "Social media and changing communication patterns", Global Media Journal-Indian Edition, Vol. 5 No. 1, p. 1.

Barnett, G.A. and Benefield, G.A. (2017), "Predicting international Facebook ties through cultural homophily and other factors", New Media and Society, Vol. 19 No. 2, pp. 217-239.

Bauer, C. and Schedl, M. (2019), A Cross-Country Investigation of User Connection Patterns in Online Social Networks, Proceedings of the 52nd Hawaii International Conference on System Sciences (HICSS 2019), Grand Wailea, Maui, HI, 8-11 January, pp. 2166-2175.

Carter, D. (2005), "Living in virtual communities: an ethnography of human relationships in cyberspace", Information Community and Society, Vol. 8, pp. 148-167.

cleric, S.A. (2014), “Twitter 'source of all evil”, Interview, (22 October 2014).

Farooq, M. (2019), Active Social Media Users in Pakistan Grow by 5.7\%: Report, Pakistan Today Profit, Lahore.

Giddens, A. (1999), Reith Lectures 1999: Runaway World, Profile Books.

Helliwell, J.F. and Huang, H. (2013), "Comparing the happiness effects of real and on-line friends", PLoS ONE, 3 September, Vol. 8 No. 9, p. e72754.

Liu, Y. (2010), "Social media tools as a learning resource", Journal of Educational Technology Development and Exchange", Vol. 3 No. 1, pp. 101-114. 
Lu, D., Sang, J. and Chen, Z. (2017), “Who are your 'real' friends: analyzing and distinguishing between offline and online friendships from social multimedia data", IEEE Transactions on Multimedia, Vol. 19 No. 6, pp. 1299-1313.

Nielson, A.C. (2012), State of the Media - The Social Media Report, The Nielsen Company (US), LLC.

Professor Andy Lane (2006), "OpenLearn”, available at: https://www.open.edu/openlearn/sciencemaths-technology/engineering-and-technology/technology/what-technology.

Ramey, K. (2013), "What is technology - meaning of technology and its use", available at: https:// www.useoftechnology.com/what-is-technology/.

Ruzgar, N.S. (2005), "A research on the purpose of Internet usage and learning via Internet", The Turkish Online Journal of Educational Technology, Vol. 4 No. 4, pp. 27-32.

Standlee, A. (2018), "Friendship and online filtering: the use of social media to construct offline social networks", New Media and Society, Vol. 21 No. 3, pp. 1-16.

Teong, K.V. and Ang, M.C.H. (2016), "Internet use and addiction among students in Malaysian public universities in east Malaysia: some empirical evidence", Journal of Management Research, Vol. 8 No. 2.

Ukomadu, C. (2018), "The role of social media in community development in Nigeria: the owe unity forum (oaf) model", IOSR Journal of Humanities and Social Science (IOSR-JHSS), Vol. 23 No. 5, pp. 34-43.

Walker, J., Dziuban, C. and Glenda, M. (2013), ECAR Study of Undergraduate Students and Information Technology, ECAR, Boulder.

\section{Corresponding author}

Asma Butt can be contacted at: asmabutt1123@gmail.com
University students' preference 